\title{
Deuterium Retention in Tungsten-doped Amorphous Carbon Films
}

\section{Exposed to Deuterium Plasma}

\author{
P. Wang, W. Jacob* , L. Gao, T. Dürbeck \\ Max-Planck-Institute für Plasmaphysik, EURATOM Association, Boltzmannstr.2, 85748 Garching, Germany
}

\begin{abstract}
:
Deuterium retention in tungsten-doped amorphous carbon $(a-\mathrm{C}: \mathrm{W})$ films with $0-9.5$ at.\% W concentration exposed to deuterium plasma was studied by nuclear reaction analysis (NRA) and thermal desorption spectroscopy (TDS). Deuterium retention of $a-\mathrm{C}: \mathrm{W}$ films decreases with increasing initial $\mathrm{W}$ concentration and increases monotonically with incident fluence. No saturation of retention was observed up to a fluence of $3.8 \times 10^{24} \mathrm{Dm}^{-2}$. All $a-\mathrm{C}: \mathrm{W}$ films with a $\mathrm{W}$ concentration lower than $9.5 \%$ show a higher deuterium retention than pure amorphous carbon films. This can be attributed to the formation of a highly porous $\mathrm{W}$ layer at the film surface. The total retained deuterium amount measured by TDS is $15-30 \%$ lower than the amount measured by NRA. The difference between these two methods is attributed to the release of deuterium in the form of long chain hydrocarbons during TDS which cannot be well quantified.
\end{abstract}

Published in: $\quad$ Journal of Nuclear Materials, 438, S1134-S1137 (2013).

doi: $\quad$ http://dx.doi.org/10.1016/j.jnucmat.2013.01.250

Available online: $\quad 20.01 .2013$

PACS: 52.40.Hf, 81.65.Cf, 82.65.+r, 52.77.Bn

PSI-20 Keywords: Carbon films; Doped-carbon; Deuterium; Plasma; Retention

*Corresponding author: Wolfgang Jacob,

*Corresponding author address: Boltzmannstr.2, 85748 Garching, Germany

*Corresponding author E-mail: wolfgang.jacob@ipp.mpg.de

Presenting author: Peng Wang

Presenting author E-mail: peng.wang@ipp.mpg.de 


\section{Introduction}

Interaction of the boundary plasma with the plasma-facing surfaces will lead to erosion of wall materials. Eroded species will be co-deposited with hydrogen isotopes on other surfaces [1-4]. Co-deposition of tritium with material eroded from the plasma-facing components is expected to be the main contribution to the tritium inventory in ITER [4-6]. According to the ITER design review, carbon and tungsten have been chosen as plasma-facing materials for the ITER divertor [6]. The use of carbon materials together with tungsten will lead to deposition of mixed carbon-tungsten layers. In this article we report on investigations regarding the hydrogen isotope retention in mixed carbon-tungsten layers. Tungsten-doped amorphous carbon $(a-\mathrm{C}: \mathrm{W})$ films deposited by magnetron sputtering were used as model systems for these investigations. In previous work [7] the carbon erosion behaviour of $a-\mathrm{C}: \mathrm{W}$ exposed to deuterium plasma has been investigated. The result showed that after D plasma exposure a porous W-rich layer is formed at the surface and the structure and thickness of the W-rich layers depend strongly on the initial $\mathrm{W}$ concentration and on the energy of the impinging ions. In the experiments presented here both thermal desorption spectroscopy (TDS) and nuclear reaction analysis (NRA) were used to investigate the deuterium retention in tungsten-doped carbon films exposed to deuterium plasma.

\section{Experimental details}

Pure and tungsten-doped amorphous carbon films with thicknesses between 600 and $800 \mathrm{~nm}$ were deposited onto single crystalline (100) silicon wafers using a commercial sputtering device (Discovery ${ }^{\circledR} 18$, Denton) comprising three individually controllable magnetrons. Two of these magnetrons, one holding a graphite and the other a tungsten target, were employed for depositing $a-\mathrm{C}: \mathrm{W}$ films using argon as sputtering gas. Pure carbon films and tungsten-doped carbon films with different tungsten concentrations were produced. More details of the deposition procedure can be found in Refs. [7, 8].

Implantation experiments were carried out in the laboratory plasma experiment PlaQ. A basic description of PlaQ is given in Ref. [9]. In short, PlaQ consists of a stainless steel chamber and is equipped with a remote electron cyclotron resonance plasma source. Microwaves $(2.45 \mathrm{GHz})$ are launched from the high B-field side through a waveguide terminated by a quartz window. The magnetic field is created by a single magnetic coil. The plasma is confined in a metallic cage $150 \mathrm{~mm}$ in height and $140 \mathrm{~mm}$ in diameter. A diverging plasma beam leaves the cage in an axial direction through a hole in the bottom plate and impinges perpendicularly onto the substrates which are located $100 \mathrm{~mm}$ below the cage exit. The energy of the ions impinging on the substrates was varied by applying an rf bias to the substrate electrode. The deuterium ion fluxes were quantified in a recent publication [9]. For a given discharge pressure of $1 \mathrm{~Pa}$ and a nominal microwave power of $144 \mathrm{~W}$ the ion fluxes at $75(30 \mathrm{eV} / \mathrm{D})$ and $285 \mathrm{~V}(100 \mathrm{eV} / \mathrm{D}) \mathrm{rf}$ bias are $4.8 \times 10^{19}$ and $5.8 \times 10^{19} \mathrm{~m}^{-2} \mathrm{~s}^{-1}$, respectively [7].

Rutherford backscattering spectrometry (RBS) using a $4.0 \mathrm{MeV}{ }^{4} \mathrm{He}$ beam was applied to measure the elemental composition of the films before and after erosion. The tungsten concentration of the film varied between 0 and 9.5 at. \%. For convenience, the notation being used throughout the text to describe a tungsten-doped amorphous carbon films containing $\mathrm{x}$ at. \% tungsten is " $\mathrm{x} \% a-\mathrm{C}: \mathrm{W}$ ". After exposure the amount of $\mathrm{D}$ retained in the samples was measured by NRA. The D concentration within the near-surface layer (at depths up to about $0.5 \mu \mathrm{m})$ was measured by means of the $\mathrm{D}\left({ }^{3} \mathrm{He}, \alpha\right) \mathrm{p}$ nuclear reaction at a ${ }^{3} \mathrm{He}$ energy of 0.69 $\mathrm{MeV}$, and the $\alpha$ particles were energy-analyzed with a small-angle surface barrier detector at the laboratory scattering angle of $102^{\circ}$. To determine the D concentration up to larger depths, the energy of the analyzing beam of ${ }^{3} \mathrm{He}$ ions was varied from 0.69 to $1.5 \mathrm{MeV}$. The protons from the $\mathrm{D}\left({ }^{3} \mathrm{He}, \mathrm{p}\right)^{4} \mathrm{He}$ nuclear reaction were counted using a wide-angle proton detector placed at a scattering angle of $135^{\circ}$. In order to determine the $\mathrm{D}$ concentration profile in the 
whole layer SIMNRA [10] was used for the deconvolution of the proton yields measured at different ${ }^{3} \mathrm{He}$ ion energies. The retained $\mathrm{D}$ amount at each energy was determined by comparing the proton counts of the measured sample and of a calibrated $a-C: D$ film with known D concentration. The total amount of $\mathrm{D}$ retention was finally obtained by integrating the $\mathrm{D}$ profile over the measured depth. The accuracy of this procedure for the determination of the D inventory is about $10 \%$.

For selected samples the retained D amount was after the NRA measurement additionally measured by TDS in the quartz tube of the TESS device. A basic description of TESS is given in [11]. The temperature response of the samples to the linear oven temperature ramp was calibrated in independent experiments by a thermocouple spot-welded to a sample. The samples were heated up to $1275 \mathrm{~K}$ with a heating rate of $0.25 \mathrm{~K} / \mathrm{s}$. For the quantitative analysis the QMS signals for $\mathrm{H}_{2}, \mathrm{HD}, \mathrm{D}_{2}$ and $\mathrm{CD}_{4}$ were calibrated using calibrated gas leaks. The amount of deuterium released from the samples was determined by integrating the QMS signals for mass $3(\mathrm{HD}), 4\left(\mathrm{D}_{2}\right)$ and $20\left(\mathrm{CD}_{4}\right)$.

\section{Results and discussion}

Fig. 1 shows the fluence dependence of the deuterium retention in $a-\mathrm{C}$ and $a-\mathrm{C}: \mathrm{W}$ films exposed to deuterium plasma at 30 (a) and $100 \mathrm{eV} / \mathrm{D}$ (b) incident particle energy. All curves show a linear increase on a double logarithmic scale with different power laws. For pure amorphous carbon $(0 \% \mathrm{~W})$ film only four data points were obtained for fluences up to $3.5 \times 10^{23} \mathrm{D} / \mathrm{m}^{2}$. This is due to the high erosion rate which leads to complete removal of the used films after this fluence. At $30 \mathrm{eV} / \mathrm{D}$ the amount of retained deuterium in the $a$-C film increases according to a power law with an exponent of 0.10 . Deuterium retention in $a-\mathrm{C}$ film increases by a factor of 2 with a slightly increased exponent $(0.13)$ at higher energy $(100 \mathrm{eV} / \mathrm{D})$. For $a-\mathrm{C}: \mathrm{W}$ films the deuterium retention behaviour strongly depends on the $\mathrm{W}$ concentration. Generally, deuterium retention in the film decreases with increasing W concentration. At $30 \mathrm{eV} / \mathrm{D}$, the amount of deuterium retention in $2.5 \% a-\mathrm{C}: \mathrm{W}$ film shows the strongest increase with an exponent of 0.34 and reaches a value of $1.4 \times 10^{21} \mathrm{D} / \mathrm{m}^{2}$ at a incident fluence of $3.5 \times 10^{23} \mathrm{D} / \mathrm{m}^{2}$. For 5 and $6.5 \% a-\mathrm{C}: \mathrm{W}$ films, deuterium retention is still higher than in pure carbon films and increases with exponents of 0.23 and 0.11 , respectively. For 9.5\% $a-\mathrm{C}: \mathrm{W}$ films the retained $\mathrm{D}$ amount increases only weakly (exponent 0.04 ) and stays below the level of the pure $a-\mathrm{C}$ film. For higher incident energy $(100 \mathrm{eV} / \mathrm{D})$ very similar general tendencies are found, but the retained D amounts and the exponents are slightly higher than for $30 \mathrm{eV} / \mathrm{D}$.

Prior investigations of $\mathrm{D}$ retention in both pyrolytic graphite and $a-\mathrm{C}$ films (identical to our films) after bombardment with a deuterium ion beam at $200 \mathrm{eV} / \mathrm{D}$ [12] have shown that these two materials have a very similar deuterium retention behavior: $\mathrm{D}$ retention increases monotonically with the same exponent of about $0.12 \pm 0.01$. In that work [12] D retention in $a$ $\mathrm{C}: \mathrm{W}$ films with 2.5 and $7.5 \% \mathrm{~W}$ concentration was also studied up to fluence of $10^{23} \mathrm{D} / \mathrm{m}^{2}$. In both cases the deuterium retention increase with fluence, but the total retained amounts are comparable to but slightly lower than those of pyrolytic graphite and $a-\mathrm{C}$ films. An obvious difference of these two experiments is that in our experiments due to the plasma exposure not only ions, but also highly reactive neutral deuterium atoms impinge on the substrates. The atom flux is at least one order of magnitude higher than the ion flux [9]. Furthermore, an additional experiment was performed in which no energetic ions but only neutral species can reach the sample surface. After exposure for $1080 \mathrm{~min}$ (the time for maximum fluence shown in Fig. 1) no loss of carbon atom could be detected by RBS and the total retained D amount corresponded to about one monolayer. 


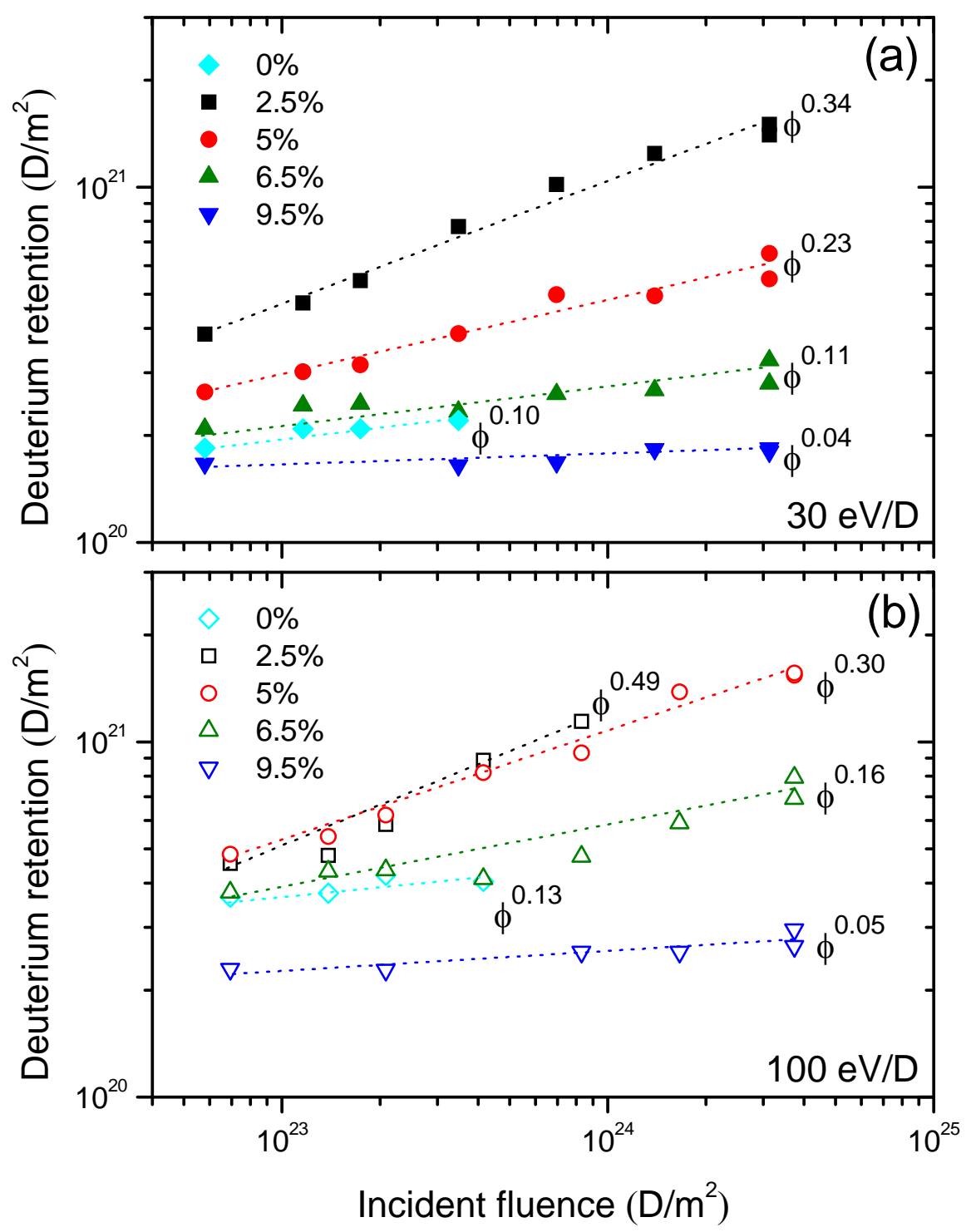

Fig. 1 Deuterium retention in $a-C$ and $a-C: W$ films exposed to deuterium plasma at an incident particle energy of 30 (a) and $100 \mathrm{eV/D}(\mathrm{b})$ as a function of the incident fluence. The percentages shown in the figure correspond to the atomic concentration of tungsten in the films.

After NRA measurement, the total deuterium retention in $a-\mathrm{C}$ and $a-\mathrm{C}: \mathrm{W}$ films were measured by TDS. Fig. 2 shows the TDS spectra of desorbed $D_{2}\left(D_{2}\right.$ contributes about $60 \%$ to the total D release) from samples exposed to the maximum fluence at 30 (a) and $100 \mathrm{eV} / \mathrm{D}$ (b) incident particle energy. For pure $a$-C films at both incident energies $\mathrm{D}_{2}$ is being released in two temperature regions. At lower temperature a clear desorption peak with the maximum at $660 \mathrm{~K}$ is found. In the higher temperature region $(700$ to $1200 \mathrm{~K})$ several desorption peaks overlap forming a broad peak. The TDS spectra of $a-\mathrm{C}: \mathrm{W}$ films consist of two to three peaks (the small sharp feature occurring in some spectra at higher temperature is an artifact of the measurement). The first peak shows up in the region from 600 to $800 \mathrm{~K}$. The second peak which is in many cases comprised of two peaks appears the region from 750 to $1100 \mathrm{~K}$. The intensity and the peak positions of $\mathrm{D}_{2}$ depend on the $\mathrm{W}$ concentration. As already shown in Fig. 1, D retention in films with a low $\mathrm{W}$ concentration is higher than in pure $a-\mathrm{C}$ films and it 
decreases with increasing $\mathrm{W}$ concentration. A definite assignment of the TDS peaks to various binding states is presently not possible and would need further experiments, but all W-doped films show a desorption peak or at least a shoulder at about 650 to $700 \mathrm{~K}$. Since we further know from our previous experiments [7] that in the $2.5 \% a-\mathrm{C}: \mathrm{W}$ film most of the carbon atoms were removed after deuterium plasma exposure at $30 \mathrm{eV} / \mathrm{D}$ and almost all at $100 \mathrm{eV} / \mathrm{D}$, and that remaining $\mathrm{W}$ atoms accumulated at the substrate with a foam-like columnar structure we can assume that the majority of the retained D released at $650-700 \mathrm{~K}$ was retained in $\mathrm{W}$, and the $\mathrm{D}$ desorbed at higher temperatures can be attributed to deuterium bonded to carbon. D desorption from pure $\mathrm{W}$ implanted and measured under comparable experimental conditions occurs at about $700 \mathrm{~K}$ [13].

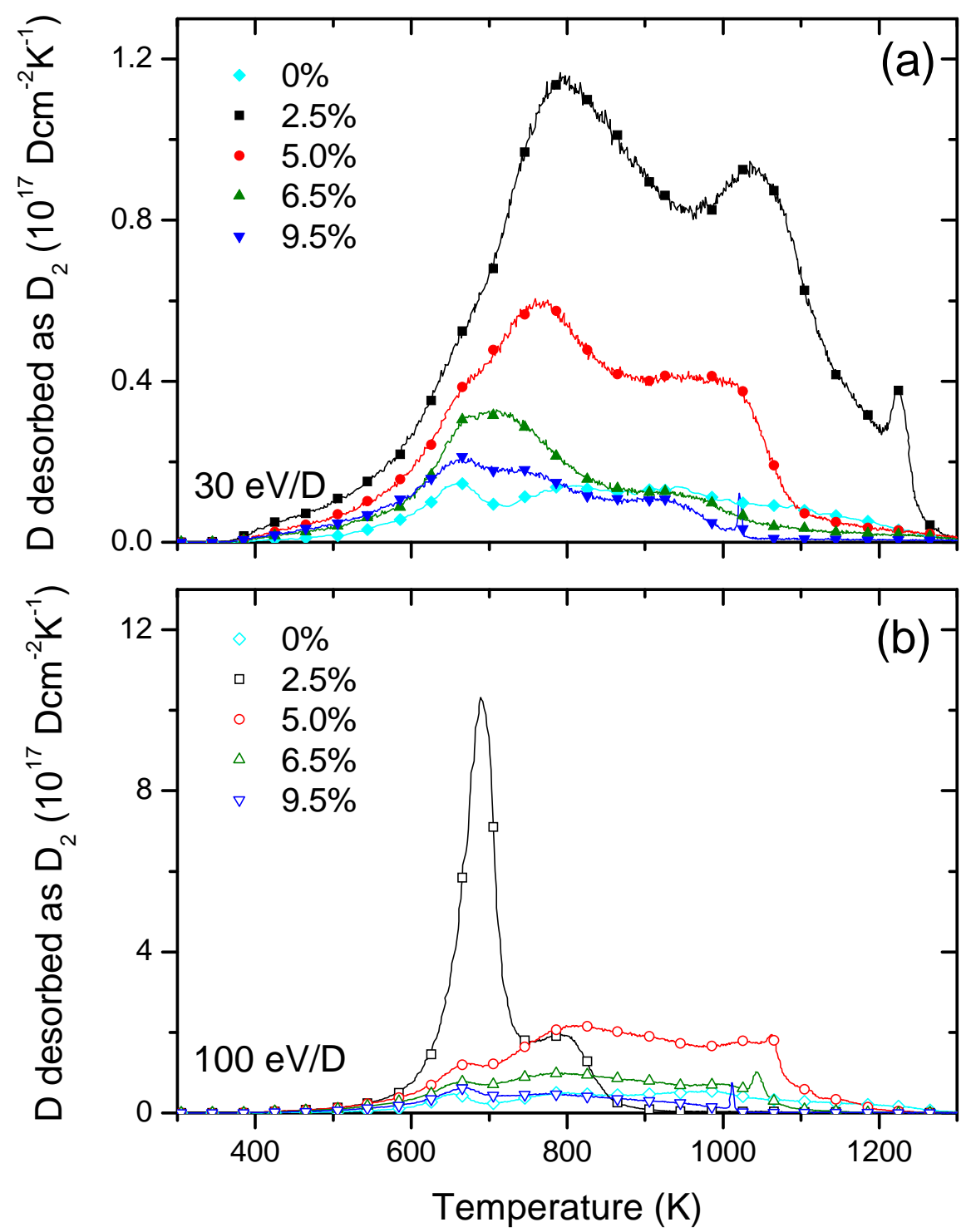

Fig. 2 Thermal desorption of D2 from a-C and a-C:W films implanted at 30 (a) and $100 \mathrm{eV/D}$ (b) incident particle energy. All samples were exposed to the corresponding maximum fluence as shown in Fig. 1 except the 2.5\% a-C:W film which was at $100 \mathrm{eV/D}$ exposed to a fluence of $1.7 \times 1024 \mathrm{D} / \mathrm{m} 2$. Note that the scale of the vertical axis is enlarged by a factor of $10 \mathrm{in} \mathrm{Fig.} 2 \mathrm{~b}$. 
The total retained deuterium amount measured by TDS is shown in Fig. 3. For comparison, the deuterium amount measured by NRA and the ratio between TDS and NRA are also plotted. In most cases the total retained deuterium amount determined by TDS is lower than that by NRA. For $30 \mathrm{eV} / \mathrm{D}$ the ratio of the two measurements is about 0.70 that means in TDS about $30 \%$ of the deuterium is not accounted for. At $100 \mathrm{eV} / \mathrm{D}$ the deuterium amount measured by TDS is $15 \%$ lower than the NRA value except one measurement point $(2.5 \% \mathrm{~W})$. One additional point has to be mentioned here: The apparent shift of the maximum $\mathrm{D}$ retention at $100 \mathrm{eV} / \mathrm{D}$ is due to the fact that at this $\mathrm{D}$ fluence most of carbon atoms in the $2.5 \% a-\mathrm{C}: \mathrm{W}$ film were removed, so that deuterium was retained only in the remaining $\mathrm{W}$ film. We assume that if a thicker initial $a-\mathrm{C}: \mathrm{W}$ would have been used $\mathrm{D}$ retention in the underlying carbon-containing film would have strongly enhanced the total retention. In TDS we observe in addition to the dominant signals for $\mathrm{D}_{2}$ and HD small signals for heavy water and many different long chain hydrocarbons. The contributions of hydrocarbons and heavy water to the total released deuterium amount cannot be quantified and are therefore not included in the shown TDS values. The contribution of heavy water was estimated to be not significant. Therefore, we attribute the difference between NRA and TDS to the occurrence of long chain hydrocarbons. Only one point $(2.5 \% a-\mathrm{C}: \mathrm{W}, 100 \mathrm{eV} / \mathrm{D})$ shows a ratio of 1 for the two measurements. For this case we know [7] that most D is retained in $\mathrm{W}$ and accordingly the contribution of hydrocarbons is negligible.

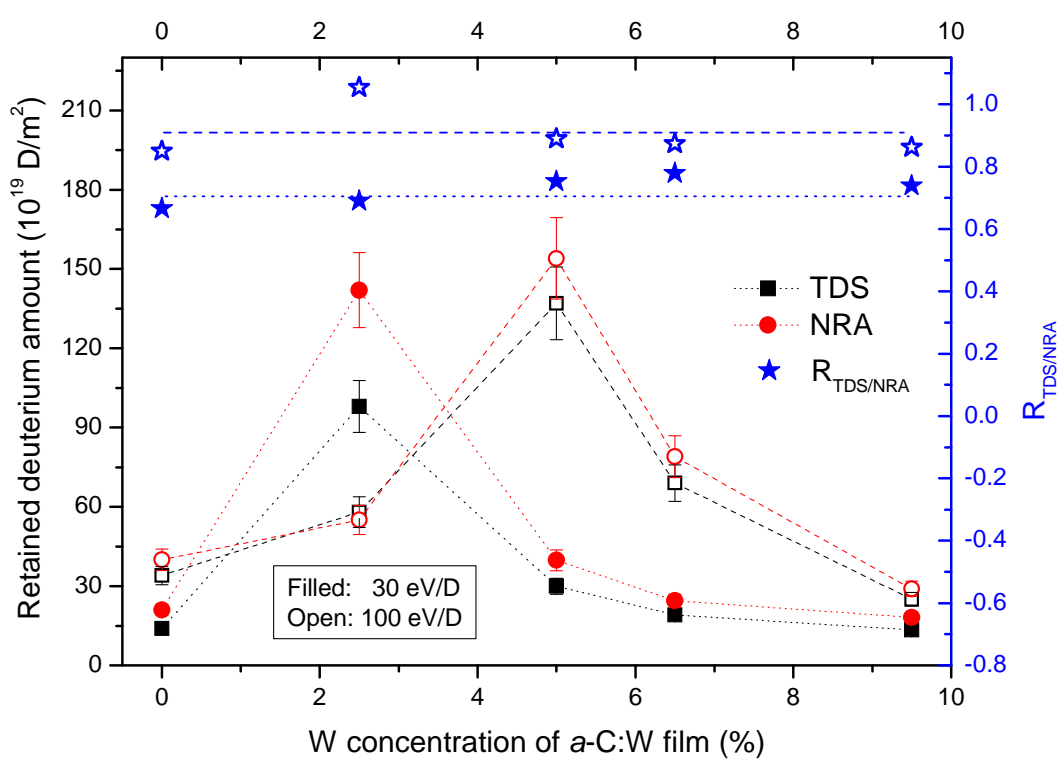

Fig. 3 Deuterium retention of a-C and a-C:W films determined by NRA and TDS at 30 (filled symbols) and $100 \mathrm{eV/D}$ (open symbols) incident particle energy. The ratios of the two measurement values are also shown (stars). All samples were exposed to the corresponding maximum fluence as shown in Fig. 1 except the 2.5\% a-C:W films at $100 \mathrm{eV} / \mathrm{D}$. For this point most carbon atoms were already removed after a fluence of $1.7 \times 1024 \mathrm{D} / \mathrm{m} 2$. Because $D$ is dominantly bonded to $C$ the absence of $C$ leads to significantly reduced retention and the apparent shift of the maximum deuterium retention to higher $W$ concentration.

Deuterium depth profiles of $a-\mathrm{C}, a-\mathrm{C}: \mathrm{W}$ and $\mathrm{W}$ films exposed to deuterium plasma at $30 \mathrm{eV} / \mathrm{D}$ incident energy are shown in Fig. 4. The deuterium atom concentration is plotted as $\mathrm{D}$ fraction relative to the local target atomic areal density determined by RBS. For the $a-\mathrm{C}$ film exposed to deuterium plasma with a fluence of $3.5 \times 10^{23} \mathrm{D} / \mathrm{m}^{2}$ the depth profile shows that most deuterium atoms are retained within the top $200 \mathrm{~nm}$ (corresponding to $1.8 \times 10^{22}$ atoms $/ \mathrm{m}^{2}$ ) with the maximum deuterium concentration of about $3 \%$. The deuterium retention in magnetron sputtered $\mathrm{W}$ films shows a completely different behaviour: After 
deuterium plasma exposure a D-rich layer with a deuterium concentration of about 1.2 at $\%$ is found in the top $10 \mathrm{~nm}$ of the surface followed by a long tail with $\mathrm{D}$ concentration below $0.3 \mathrm{at} \%$ extending throughout the whole $2 \mu \mathrm{m}$ thick $\mathrm{W}$ film. In the $2.5 \% a-\mathrm{C}: \mathrm{W}$ film the maximum $\mathrm{D}$ concentration at the near surface reaches $11 \mathrm{at} \%\left(3.1 \times 10^{24} \mathrm{D} / \mathrm{m}^{2}\right.$ incident fluence). This is about one order of magnitude higher than that of the magnetron sputtered $\mathrm{W}$ films and it is also 3 to 4 times higher than in pure $a-\mathrm{C}$. To understand the D retention in $a-$ $\mathrm{C}: \mathrm{W}$ films the change of film structure during plasma exposure has to be taken into account. During interaction with the D plasma carbon atoms are preferentially eroded and $\mathrm{W}$ atoms are enriched at the surface. In our previous work [7], an identical sample was used to make crosssection images which show that after plasma erosion the film thickness decreases from $760 \mathrm{~nm}$ to $600 \mathrm{~nm}$. The top $300 \mathrm{~nm}$ of this film are pure W with a foam-like structure with $95 \%$ porosity. The NRA depth profiles show that the deuterium atoms are retained in the whole remaining $600 \mathrm{~nm}$ thick layer. For $5 \%$ a-C:W the maximum D concentration decreases to $4 \mathrm{at} \%$. From the SEM cross-section images [7] we found for this film a relatively compact ( $85 \%$ porosity) $\mathrm{W}$-rich layer of about $70 \mathrm{~nm}$ at the surface. The total remaining film thickness is about $740 \mathrm{~nm}$. From the $\mathrm{D}$ depth profile we see that $\mathrm{D}$ penetrates this $\mathrm{W}$-rich layer and reaches a depth of $2.5 \times 10^{22}$ atoms $/ \mathrm{m}^{2}$ which corresponds to about $300 \mathrm{~nm}$ if the bulk density of amorphous carbon is used [14]. That means that $\mathrm{D}$ does not diffuse into the whole remaining $a-\mathrm{C}: \mathrm{W}$ layer and does not reach the interface to the Si substrate. For $9.5 \% a-\mathrm{C}: \mathrm{W}$ film the total retained deuterium amount reduces to close to the level of pure $a$-C. The crosssection images [7] showed a dense $20 \mathrm{~nm}$ thick W-rich layer at the surface, which protects carbon atoms under it from further erosion. The maximum D concentration in the W-rich layer is $1.4 \mathrm{at} \%$, which is slightly higher than the $\mathrm{D}$ concentration in the reference $\mathrm{W}$ film. Below the W-rich layer deuterium atoms reach a depth of $2.0 \times 10^{22}$ atoms $/ \mathrm{m}^{2}$ (about $240 \mathrm{~nm}$ ). This value is almost as the same as the deuterium diffusion into amorphous carbon. That also means that although this $20 \mathrm{~nm}$ thick W-rich layer is sufficiently dense to prevent further erosion, it does not block D penetration into the underlying film.

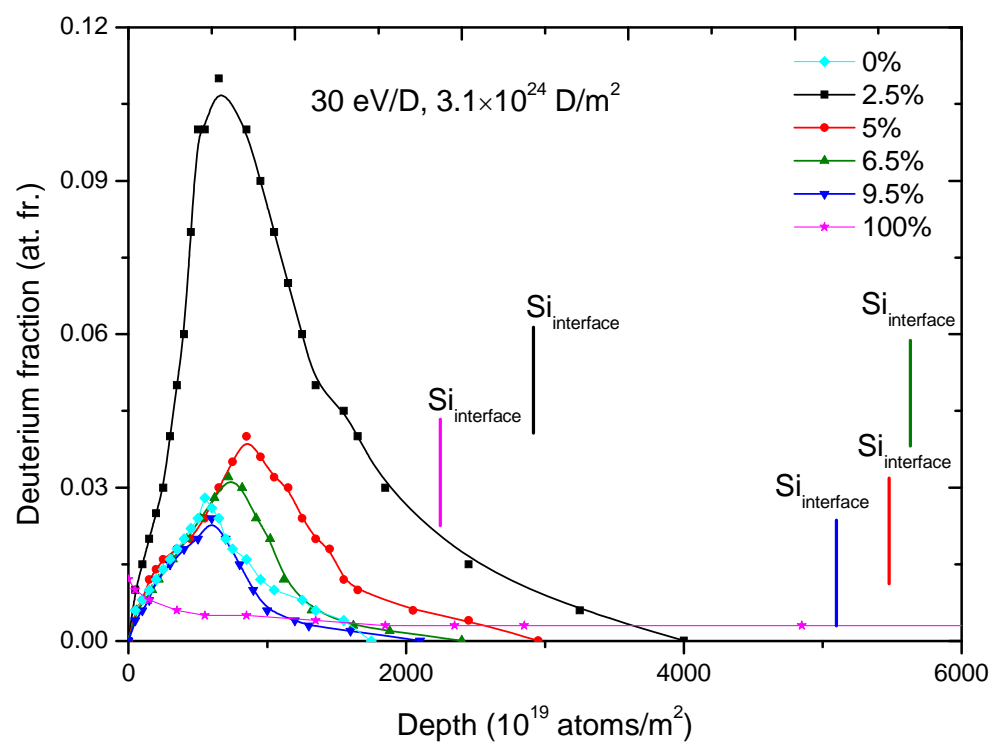

Fig. 4 Deuterium depth profiles of a-C:W films exposed to deuterium plasma at $30 \mathrm{eV} / \mathrm{D}$ incident particle energy with different incident fluences: $3.5 \times 1023 \mathrm{D} / \mathrm{m} 2$ for a-C film and $3.1 \times 1024 \mathrm{D} / \mathrm{m} 2$ for others. The interfaces between the remaining films and the silicon substrates are marked in figure with different colors. Note the depth scale is the areal density determined by RBS. The percentages shown in the figure correspond to the atomic concentration of tungsten in the films. 
Obviously, the formation of the highly porous $\mathrm{W}$ layer at the sample surfaces not only provides many transport pathways allowing deep penetration of atomic particles into the bulk of the layers but also plays an important role for retention of deuterium within it. On the other hand, the formation of these relatively compact W-rich surface layers leads to an increase of the reflection coefficient for impinging ions, and as a result deuterium retention in the film decreases.

\section{Conclusion}

Tungsten-doped amorphous carbon films deposited by magnetron sputtering were used as model systems for tungsten-containing redeposited layers. The fluence dependence of the deuterium retention in $a-\mathrm{C}: \mathrm{W}$ films exposed to deuterium plasma at 30 and $100 \mathrm{eV} / \mathrm{D}$ incident particle energy was studied by NRA and TDS. The deuterium retention in $a$-C:W films increases monotonically with incident fluence and decreases with increasing initial W concentration. No saturation of retention was observed up to a fluence of $3.8 \times 10^{24} \mathrm{Dm}^{-2}$. Compared to amorphous carbon films which show the same deuterium retention behavior as pyrolytic graphite all investigated $a-\mathrm{C}: \mathrm{W}$ films except the $a-\mathrm{C}: \mathrm{W}$ film with $9.5 \% \mathrm{~W}$ concentration show a higher deuterium retention. The main reason for the increase of deuterium retention in $a-\mathrm{C}: \mathrm{W}$ films is the formation of a highly porous $\mathrm{W}$-rich layer at the surface of film, which not only provides many transport paths allowing deep penetration of atomic hydrogen species but contributes to enhanced retention compared with pure $\mathrm{W}$ films.

\section{Acknowledgements}

The stay of P. Wang at Max-Planck Institute for Plasma Physics in Garching was funded through a bilateral agreement between Max-Planck Society and the Chinese Academy of Sciences which is gratefully acknowledged. Thanks are further due to Michael Fußeder and Joachim Dorner for help with the RBS measurements.

\section{References}

[1] W. Jacob, J. Nucl. Mater. 337-339 (2005) 839

[2] C. K. Tsui, A. A. Haasz, J. W. Davis, J. P. Coad, J. Likonen, Nucl. Fusion. 48 (2008) 035008.

[3] G. Federici, C. H. Skinner, J. N. Brooks, et al., Nucl. Fusion. 41 (2001) 1967.

[4] J. Roth, E. Tsitrone, A. Loarte, J. Nucl. Mater390-391 (2009) 1.

[5] R. A. Causey, J. Nucl. Mater. 300 (2002) 91.

[6] R.J. Hawryluk et al., Nucl. Fusion 49 (2009) 065012.

[7] P. Wang, W. Jacob, M. Balden, T. Höschen, A. Manhard, J. Nucl. Mater. 426 (2012) 277.

[8] M. Balden, B. T. Cieciwa, I. Quintana, E. de Juan Pardo, F. Koch, M. Sikora, B. Dubiel, Surf. Coat. Technol. 200 (2005) 413.

[9] A. Manhard, T. Schwarz-Selinger, W. Jacob, Plasma Sources Sci. Technol. 20 (2011) 015010 .

[10] M. Mayer, „SIMNRA User's Guide“, IPP Report Number: IPP 9/113, Max-PlanckInstitut für Plasmaphysik, Garching (1997).

[11] E. Salançon, T. Dürbeck, T. Schwarz-Selinger, F. Genoese and W. Jacob, J. Nucl. Mater. $376(2008) 160$.

[12] P. A. Sauter, M. Balden, Phys. Scr., T138 (2009) 014044.

[13] A. Manhard, U. V Toussaint, T. Dürbeck, K. Schmid, W. Jacob, Phys. Scr. T145 (2011) 014038.

[14] P. Wang, W. Jacob, M. Balden, A. Manhard, T. Schwarz-Selinger, J. Nucl. Mater. 420 (2011) 101. 